\title{
Indio (denominación) Indian (denomination)
}

\author{
Yaneth Katia Apaza Huanca \\ Red de Derechos Humanos IDHBC \\ vivanka333@gmail.com
}

Recibido / received: 31/08/2018

Aceptado / accepted: 31/01/2018

DOI: https://doi.org/10.20318/eunomia.2018.4165

\section{Resumen}

El artículo mostrará cómo las distintas denominaciones: indio, pueblo indio o indígena, campesino, comunidad indígena u originaria, etnia, nación y nacionalidad, otorgadas a los aymaras, quechuas (Bolivia) y kichwas (Ecuador) son una deconstrucción histórica social de casi cinco siglos hacia su identidad milenaria e histórica, que causan tres efectos: a) dominación (tutela), b) desestructuración territorial, por ende, desarticulación políticoadministrativa, económica y social, y c) limitación en su lucha por la emancipación.

Así, las distintas denominaciones usadas por los Estados plurinacionales de Bolivia y Ecuador, son un lenguaje hegemónico-histórico deconstructivo por medio de significantes y significaciones que impregnará un "signo" colonial y postcolonial a los jaques, runas, ayllus, markas, suyus, señoríos aymaras, quechuas, y kichwas convirtiéndose a largo plazo en un paradigma de la denominación y dominación.

\section{Palabras clave}

Aymaras, quechuas, kichwas; paradigma de la denominación y dominación; significante; significación; colonial; postcolonial; deconstrucción; tierra y territorio.

\begin{abstract}
The article will show how the different denominations: Indian, Indian or indigenous people, peasant, indigenous or native community, ethnicity, nation and nationality, granted to the Aymaras, Quechuas (Bolivia) and Kichwas (Ecuador) are a social historical deconstruction of almost five centuries towards its millenarian and historical identity, which causes three effects: a) domination (guardianship), b) territorial destructuration, therefore, political-administrative, economic and social disarticulation, and c) limitation in its struggle for emancipation.

Thus, the different denominations used by the Plurinational States of Bolivia and Ecuador, are a hegemonic-historical deconstructive language by means of signifiers and significations that will impregnate a colonial and postcolonial "sign" to the jaques, runas, ayllus, markas, suyus, señoríos Aymaras, Quechuas, and Kichwas become a paradigm of denomination and domination over the long term.
\end{abstract}

\section{Keywords}

Aymaras, Quechuas, Kichwas; paradigm of denomination and domination; significant; significance; colonial; postcolonial; of construction; land and territory. 
SUMARIO. 1. De la deconstrucción denominativa por medio de significantes y significaciones. 2. Origen del paradigma de la denominación y dominación. 3. La desestructuración territorial a través de República de indios y de españoles. 4. Nacimiento de los Estados republicanos de Bolivia y Ecuador: los aymaras, quechuas y kichwas sin ciudadanía. 5. Los Estados nacionales y el "problema a resolver". 6. El multiculturalismo liberal y su reconocimiento como "etnias". 7. La plurinacionalidad, un reconocimiento ajeno a su identidad. 8. Reflexiones finales.

1. De la deconstrucción denominativa por medio de significantes y significaciones Las denominaciones utilizadas hacia los jaques y/o runas (seres humanos), ayllus (comunidad), markas (conjunto de ayllus), suyus (conjunto de markas), señoríos aymaras, quechuas de Bolivia y kichwas del Ecuador, nombrándolos cómo indios, pueblos indios, indígenas, campesinos, comunidades indígenas u originarias, etnias, naciones y nacionalidades, son una historia de continua deconstrucción denominativa occidental que atraviesa cinco períodos o cinco siglos históricos coloniales y postcoloniales (Apaza Huanca, 2016).

Es una deconstrucción ${ }^{1}$ denominativa, es decir, un desmonte conceptual histórico porque trastoca directamente a su ser o identidad inter-relacionada en un todo - geográfico, político, económico y social一. Él mismo se manifiesta bajo un lenguaje hegemónico de características indigenistas y neo-indigenistas, utilizando distintos significantes (denominativos) y significaciones (formas de interpretarlos) a lo largo de la historia, que impregnará en el ser aymara, quechua y kichwa un signo (forma de reconocimiento) colonial y postcolonial no perecedero.

A largo plazo, este lenguaje hegemónico (deconstructivo) se convertirá en un paradigma ${ }^{2}$ natural de denominación y hacia la dominación, porque lo empezarán a interpretar con creencias e ideas equivocadas, cuyos alcances se reflejarán en lo jurídico, político, económico y social.

Es por ello que el paradigma descrito a lo largo de este artículo, nos expresará dominio del lenguaje de identificación, como parte de la expresión del poder. Consecuentemente, el lenguaje los homogenizará, los mantendrá invariables (estático) en una interpretación colonial histórica anacrónica, desestructurando y distorsionando su identidad. Finalmente, creará una dualidad en la forma de pensar y ser en la identidad aymara, quechua y kichwa negando el sentido de conciencia colectiva de identificación en lo geográfico, político, económico, y social (Apaza Huanca, 2016: 165-171).

\footnotetext{
${ }^{1}$ Para comprender el término deconstrucción, nos ceñiremos a lo desarrollado por el filósofo Jacques Derrida en su obra De la gramatología (1967), quien nos invita a abandonar la racionalidad, la cual dirige la escritura, puesto que ya no surge de un logos, sino que inaugura la destrucción, la deconstrucción de las significaciones, en particular la significación de la verdad (1998: 9).

2 Para el término paradigma utilizaremos la definición de Mario Bunge, que a continuación interpretamos. Para él, un paradigma contiene: $\mathrm{P}=<\mathrm{B}, \mathrm{H}, \mathrm{P}, \mathrm{A}, \mathrm{M}>$, donde $P$, es un conjunto $B$ de conocimientos de trasfondo, es decir el contexto de la historia, que junto a un conjunto $H$ de hipótesis específicas del tema, o las suposiciones acerca de su identidad, e ideas dominantes coloniales y postcoloniales, contienen una problemática $P$, o un conjunto de problemas, además un objetivo $A$, continuar con el dominio y tutela, y una metódica $M$, que vendría a ser la apropiación del lenguaje (Bunge, 2001: 159).
} 
2. Origen del paradigma de la denominación y dominación

La deconstrucción denominativa hacia su identidad mediante el lenguaje surgirá a través del significante "indio" otorgado a las "nuevas gentes" que habitaban en las nuevas tierras descubiertas. De acuerdo con Bartolomé de las Casas, Cristóbal Colón creía haber llegado a las Indias Occidentales (De las Casas y Saint-Lu, 1986: 39), de ahí el denominativo "indio". Pronto el significado de quienes eran denominados con ese significante estará referido al sometimiento por medio de la esclavitud, aunque jurídicamente fueron considerados vasallos libres de la Corona de Castilla (Borah, 1985: 257, 258).

Sin embargo, según Bartolomé de las Casas (1975: 24-27) la mayoría de los conquistadores y colonizadores estaban seguros de que los indios eran bestias o casi bestias, por ello el dominico Bernardo de Minaya fue hasta Roma a obtener la bula Sublimis Deus del papa Paulo III en 1537, cimentado en la doctrina cristiana de que los indios americanos eran criaturas ${ }^{3}$; por tanto, seres racionales.

Con todos estos antecedentes históricos, en 1532-1570 se conquista el Imperio Incaico (Cusi, 1973: 9) o Tawantinsuyo, habitado por los jaques, runas, ayllus, markas, suyus, señorios, aymaras, quechuas y kichwas, por lo que el significante indio y su significado, será asociado a "ellos", iniciando una deconstrucción o quiebre identitario en el ser aymara, quechua y kichwa y una desestructuración de su organización milenaria.

Posteriormente, en 1546, los conquistadores añadirán otro denominativo el de "pueblos indios", debido a la falta de comprensión de la organización milenaria de los aymaras, quechuas y kichwas. Resolviéndose en ese entonces que los indios fuesen reducidos a "pueblos" y no viviesen divididos (España, 1973: 198-201).

Años más tarde, en la famosa Junta de Valladolid (1550-1551) ${ }^{4}$, se otorgará otro significante o denominativo histórico, el de "gentes bárbaras". Su significado estará relacionado a que ciertos hombres son esclavos por naturaleza según la teoría aristotélica (Hanke, 1958) defendido por Juan Ginés de Sepúlveda en el Demócrates alter, sive de iustis belli causis apud indos, o "El tratado sobre las justas causas de la guerra contra los indios" (Ginés de Sepúlveda, 1982).

Así, todo ese conjunto de significantes: indio, pueblos indios, gentes bárbaras y la relación con sus significados - bestias o casi bestias, esclavos, vasallos libresotorgado por los conquistadores, será el inicio de la imposición de un sistema de ideas y creencias equivocadas (paradigma), expandidas en la sociedad y prescritas formalmente mediante normas jurídicas.

Por lo que se da inicio al paradigma de la denominación y dominación por medio de un lenguaje hegemónico, donde el sujeto colonizado será construido con metáforas y metonimias coloniales en un inicio, afirmándose como postcolonial y no perecedero en los siguientes siglos.

\footnotetext{
${ }^{3}$ Suponemos que Bernardo de Minaya se basó en Marcos 16:15: "Y les dijo: Id por todo el mundo y predicad el evangelio a toda criatura" (De Reina, 1960: 787).

${ }^{4}$ La Junta de Valladolid dilucidó sobre la legitimidad o ilegitimidad de la conquista y la condición de los indios.
} 
3. La desestructuración territorial a través de la República de indios y de españoles La línea divisoria estamental jurídica que se había planteado con la creación de "pueblos indios" a través de las reducciones, será afirmada durante el periodo colonial propiamente dicho $\left(1570-1809,1825^{5}\right)$ por medio de las Reformas de Reducción del Virrey Toledo en 1572, concentrando a los aymaras, quechuas y kichwas en "comunidades y parroquias" —significante—al estilo español (Málaga Medina, 1974: 43-71), facilitando de esta forma su administración política y económica. Por tanto, su significación estará relacionada al servicio y como objeto de instrumentalización humana.

La Recopilación General de las Leyes de Indias de $1680^{6}$ afirmará esas sociedades paralelas, separando a la población en la República de Indios o pueblos indios, y la República de Estados Españoles, de Dios o Villa de Españoles, cada una con su propio sistema de autoridades y normas, quedando la República de Indios sometida a la República de Españoles (Cabedo Mallol, 2004: 83). Así lo confirma su Libro Sexto, Título III, y más específicamente la Ley XXI en la que se prohibía que en los pueblos indios, vivieran españoles, negros, mestizos o mulatos (España, 1973: 198-201).

Otra consecuencia de las Leyes de Indias al insertar un conjunto de normas sobre la regulación-administración de los indios en "pueblos indios" en los repartimientos y encomiendas (Título VIII), es que la misma negará la forma de organización milenaria de los aymaras, quechuas y kichwas dando lugar al no reconocimiento del ayllu o comunidad. Este se conforma de familias pequeñas o troncos familiares, los cuales forman otra unidad mayor llamada marka/llajta, así la unidad de varias markas/llajtas, constituirán los layas/wamanis/señorios, y la unidad de varias layas/wamanis/señorios establecerán los suyus, extendiéndose en cuatro grandes suyus: Kollasuyu, Antisuyu, Chinchaisuyu y Kontisuyu, constituyendo todos juntos el gran Imperio de los Incas o Tawantinsuyu.

$Y$ aunque, en un inicio, las Leyes de Indias recogían una finalidad espiritual evangelizadora para cumplir los fines del repartimiento y la encomienda (Título VIII, Ley I) con el tiempo estas instituciones serán completamente desvirtuadas, puesto que, por intermedio de las reducciones de los indios en "pueblos indios", se realizaran actos de donación, venta, traspaso, permuta, alquiler, prenda, renunciación, ampliándose su administración a monasterios, hospitales, casas de religión, prelados y otros, llegándose a prohibir tal aberración (Título VIII, Ley XVI, XVII). Este dato nos permite afirmar que los significantes "indio" y "pueblo indio", estarán muy relacionado con el significado de objeto e instrumento humano.

Por otra parte, el aymara, quechua y kichwa comienza a aceptar su "identidad india" con resultados en la forma de vida dual; es decir, aceptará la denominación y dominación y por otra mantendrá vivos los elementos identitarios del ser aymara, quechua y kichwa, tales como la lengua, la forma de organización subalternizada y otros.

\footnotetext{
${ }^{5}$ Aunque algunos historiadores datan a 1560, nosotros tomamos la fecha de 1570 debido a que ese año muere Atahualpa, último gobernante del imperio inca. Finalizará este periodo con la fundación de las repúblicas en cuestión (Apaza Huanca, 2016: 15-30).

${ }^{6}$ En síntesis, eran las Leyes de Burgos, las Leyes Nuevas y las Ordenanzas de Alfaro, ordenadas en 9 libros que contienen alrededor de 6400 normas.
} 
4. Nacimiento de los Estados republicanos de Ecuador y Bolivia, los aymaras, quechuas y kichwas sin ciudadanía

La identidad deformada y dual de los aymaras, quechuas y kichwas como resultado de la denominación "indio, pueblo indio", continuará en la etapa de la creación de los Estados republicanos (1809-19607) de Bolivia (1825) y Ecuador (1809), siendo esta una etapa postcolonial ${ }^{8}$, porque, si bien surgen Estados independientes, estos no dejaran de estar articulados en las antiguas formas de administración de las sociedades coloniales.

Y si las sociedades coloniales estaban bajo la administración de los españoles, en esta nueva forma de Estado postcolonial, los herederos del poder serán los criollos. Representados por la nueva élite, los terratenientes, quienes encarnarán figurativamente su capacidad de imaginarse a sí mismos como comunidades paralelas y comparables a las de Europa.

En esta nueva sociedad la mayoría de la población serán los denominados indios y/o pueblos indios, e insertos en esa identidad estarán los aymaras, quechuas y kichwas quienes serán homogeneizados con un nuevo denominativo el de "indígena". Este significante impulsará su anonimidad y por ende la continua deconstrucción de su identidad como un "todo inter-relacionado", porque el mismo involucra lo geográfico, lo político-administrativo, lo económico y lo social (Apaza Huanca, 2016).

La deconstrucción desde lo geográfico (tierra y territorio) se dará porque los nuevos Estados se conformarán con otro tipo de límites geográficos, muy distintos a la organización milenaria de los ayllus, markas, suyus, señorios aymaras, quechuas y kichwas. Por otra parte, los Estados nacientes con mirada europea y ausentes de la identidad aymara, quechua y kichwa crearán una nueva categoría jurídica y política, la "ciudadanía", concedida a "hombres libres" (Guerrero, 1994) que sabían leer y escribir (Bolivia) y habían adquirido un determinado patrimonio económico

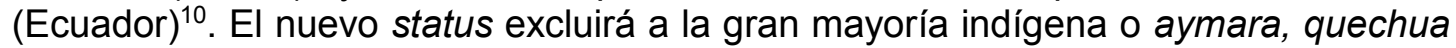
y kichwa de la participación política, jurídica, economía y social de los nuevos Estados.

Un momento álgido será el periodo 1850-1880, un momento histórico autoritario en la política en los Estados republicanos, porque estará impregnado de un positivismo y racismo en el pensamiento criollo. Las relaciones entre indígenas (aymara, quechua, kichwa) y Estado serán más conflictivas, porque empezarán a deshacer sus estructuras etnopolíticas y jurídicas, exterminándolos (Thurner, 2001: 175-176).

Además, las nuevas ideas liberales basadas en la igualdad ciudadana abolirán el tributo del indio. Esto dará como resultado reformas tributarias tendentes a liquidar las formas comunales de la tierra o ayllus. De este modo los aymaras, quechuas y

\footnotetext{
${ }^{7}$ La organización republicana del Ecuador durará hasta 1895. En Bolivia, el Estado republicano se extiende hasta 1900.

${ }^{8}$ El artículo se enmarca en la teoría postcolonial, una postura crítica, la cual trata aspectos sobre las sociedades que han sufrido el colonialismo británico y francés. De sus representantes hemos estudiado en especial, los análisis de Homi K. Bhabha.

${ }^{9}$ Interpretado por el diccionario de la Academia Francesa (1798) como el natural de un país y habitante de América (Ramírez, 2011).

${ }^{10}$ Art. 14 de la Constitución Política de Bolivia de 1826 y art. 12 de Constitución Política del Estado del Ecuador 1830.
} 
kichwas serán victimas de usurpación de sus tierras comunales, siendo su situación peor que en la Colonia.

Esta situación se irá agravando porque convertirán a los ayllus, markas, suyus, señorios aymaras, quechuas de Bolivia en grandes haciendas y a sus habitantes en pongos y colonos. En Ecuador, la situación de los kichwas será casi similar o peor, porque el régimen dominante en las haciendas será el "concertaje" de origen colonial ${ }^{11}$. Más tarde este será reemplazado con el "huasipungo" cuya característica singular, es la de ser una relación de dominación ${ }^{12}$.

Por lo que en este periodo el significante o denominación indígena y su relación con su significación pongo, colono, siervo, será como una moneda de dos caras, que llevará a los aymaras, quechuas y kichwas a un continuo signo histórico de dominio y tutela.

\section{Los Estados nacionales y el "problema a resolver"}

Históricamente, este es el momento de la búsqueda de una sola identidad, a partir del sistema político nacionalista. En Bolivia, se establecerá desde 1900 a 1980 y en la misma línea seguirá Ecuador desde 1912 a 1984. El nacionalismo estará acompañado por ideas de la época como el positivismo, darwinismo, marxismo y comunismo. Esas ideologías predominantes influenciarán con políticas económicas y sociales a los Estados con respecto a la forma de administrar a los "indios e indígenas" (Apaza Huanca, 2016: 44). Por ende, el objetivo del Estado será buscar una raza, una lengua, y una cultura común.

Sin embargo, su objetivo no podrá ser cumplido porque la realidad es otra. Una sociedad heterogénea en población, por lo que empieza a surgir en el consciente de los terratenientes la idea del conflicto a resolver por el "problema humano" al cual gobiernan; es decir, que los indios, indígenas y pueblos indios tendrán esa nueva significación. Por otra parte, el indigenismo naciente en varios países como México, Perú, Bolivia ${ }^{13}$, se convertirá en $1940^{14}$ en una política oficial de los Estados de América, definiendo al indígena como un individuo económica y socialmente débil.

En 1938, en Bolivia y a nivel normativo, se promulgará la nueva Constitución Política del Estado regulando nuevos Regímenes, entre ellos el del "Campesinado", en el que encontramos dos nuevas denominaciones o significantes: comunidades indígenas (art. 165) y campesino (art. 167).

Con estos dos significantes se dará lugar a una nueva clase social, por medio de la cual se agrupará y organizará el $1^{\circ}$ Congreso Campesino de Bolivia (La Paz), impulsando una nueva etapa de conformación de "sindicatos campesinos" en 1945 (Gotkowitz, 2007: 209). A partir de este, los ayllus, markas, suyus, señorios aymaras y quechuas en Bolivia se asimilarán como "sindicatos campesinos" e irán perdiendo cada vez más su identidad en cuanto a la composición de su territorio.

En 1953, la Ley de Reforma Agraria (N. ${ }^{\circ}$ 3463) afirmará estos significantes legalizando la existencia de sindicatos campesinos (art. 132) creando un minifundio

\footnotetext{
11 Cédula del 24 de noviembre de 1601.

12 Los patrones endeudarán a los indígenas con anticipos, serán atados económicamente a las haciendas no pudiendo cancelar sus deudas (Guerrero, 1991).

${ }^{13} \mathrm{El}$ indigenismo pasa por varias etapas y enfoques en los distintos países. Nació con una justificación teórica en defensa de los indígenas, pero posteriormente se convertirá en una política de protección y tutela al indígena.

${ }^{14}$ La Convención de Pátzcuaro de 1940 hace énfasis en medidas de protección de parte de los gobiernos y su asimilación.
} 
desproporcional, el cual permitirá que a largo plazo los indígenas, ahora campesinos, migren a las grandes urbes de manera individual y colectiva, formando posteriormente federaciones de campesinos y el cual impulsará, la Confederación Sindical Única de Trabajadores Campesinos de Bolivia (CSUTCB) en 1979.

El nacionalismo y el indigenismo en el Ecuador también influirán en la interpretación del significante y significación indígena. Esto se verá en el primer movimiento social campesino e indígena, la Federación Ecuatoriana de Indios (FEI) en 1926 y en el primer Código del Trabajo en 1936. En 1937, se promulgará la Ley de Organización y Régimen de las Comunas y el Estatuto Jurídico de Comunidades Campesinas. Este tendrá por objetivo crear otras formas de organización distintas a los sindicatos agrarios campesinos-indígenas.

Sin embargo, contradictoriamente, él mismo logrará fortalecer a las haciendas latifundistas y debilitará la organización de los ayllus, puesto que en la Ley se establecía un criterio general para incorporar agrupamientos de población que tuvieran un mínimo de cincuenta habitantes, desestructurando a la organización milenaria de los kichwas.

En los años 70, el indigenismo empieza a quebrarse como ideología ${ }^{15}$. Nacerá en oposición, la ideología del indianismo en Bolivia (1970-1980) como la respuesta revolucionaria de los indios al indigenismo, cuyo fin será atacar las teorías que habían justificado la subordinación por medio de la integración de los indígenas a la sociedad civil (Zárate, 2001: 27). Y si bien el indianismo será una ideología con fuertes matices de asunción política, también se observa que la denominación (significante) colonial y postcolonial de indio, indígena, campesino ya ha arraigado en su identidad.

6. El multiculturalismo liberal y reconocimiento

A mediados de los años ochenta, la forma de Estado monocultural entrará en crisis y se instalará dentro de los Estados un nuevo modelo con una propuesta normativa asociada a la dimensión fáctica a través del multiculturalismo liberal, a partir del cual se buscará cambiar la exclusión de los pueblos indígenas por el déficit histórico en el que habían vivido por siglos.

En 1985, en Bolivia, se instalará un nuevo modelo económico, el cual impulsará las Reformas Estructurales de Primera Generación, seguidas por las de Segunda Generación y Tercera Generación. Estas reformas neoliberales darán lugar a un proceso de marginalización y disconformidad, surgiendo durante este tiempo continuos levantamientos "indígenas" y protestas, cuyo objetivo será el reconocimiento de su identidad y territorio.

Esto dará lugar a la primera reforma de la Constitución Política del Estado (1994) modernizando 35 disposiciones referidas a los pueblos indígenas. El primer cambio fundamental será el de la naturaleza del Estado boliviano, el cual pasará a ser multiétnica y pluricultural (art. 1).

En Ecuador, durante los años noventa, los movimientos indígenas alcanzarán protagonismo y consolidarán su propio programa étnico cultural, organizando y reivindicando su carácter de "pueblos y nacionalidades indígenas" en defensa de sus derechos fundamentales. En 1998, lograran la promulgación de una nueva Constitución la cual declarará al Estado como pluricultural y multiétnico (art. 1) y expresará que los pueblos indígenas se autodefinen como nacionalidades (art. 83).

\footnotetext{
${ }^{15}$ Así lo expresará el Instituto Indigenista Interamericano (Marroquín, 1972: 286).
} 
Así, encontramos en ambos Estados cómo los indios, indígenas, campesinos y pueblos indios (aymaras, quechuas y kichwas) serán reconocidos con un nuevo significante, el de "etnias" y en Ecuador además de ello, como "nacionalidades". Sin embargo, la significación colonial y postcolonial heredada no cambiará, puesto que seguirán siendo ciudadanos de segunda categoría.

$\mathrm{Y}$, si bien es una época de reivindicación de los derechos de los denominados pueblos indígenas con la ratificación del Convenio N. ${ }^{\circ} 169$ de la Organización Internacional del Trabajo (OIT) de parte de Bolivia (1991) y Ecuador (1998), a su vez los Estados realizarán una desconstitucionalización o de vaciamiento de su eficacia práctica (Mazariegos, 2014: 320-321)

7. La plurinacionalidad, un reconocimiento ajeno a su identidad

Durante la década de los años dos mil, se vivirán cambios radicalmente distintos en ambos Estados. En Bolivia, en el año 2006, se instalará la Asamblea Constituyente, como una forma de refundar el Estado boliviano a través de la inclusión de la diversidad étnica y cultural y una forma de incluir a los denominados indígenas porque habían sido ignorados durante siglos.

Posteriormente, en el año 2009, se promulgará la nueva Constitución Política del Estado, reconociendo a Bolivia como un Estado plurinacional comunitario; es decir, compuesto por treinta y seis "naciones y pueblos indígenas originarios campesinos (art. 5)", dentro del cual se encontrarán los aymaras y quechuas.

Lo singular de esta nueva Constitución en cuanto a las denominaciones es que unirá históricamente varios significantes coloniales y postcoloniales al reconocerlos como naciones y pueblos indígenas originarios campesinos (arts. 30.1, 2 y 5). Esto nos demuestra la complejidad histórica y dialéctica que vive la sociedad boliviana.

La misma línea seguirá Ecuador el año 2007, convocando a una Asamblea Constituyente de la cual serán parte los indígenas. En el año 2008, se promulgará la Constitución y se declarará a Ecuador como un Estado plurinacional, además de reconocerles como comunas, comunidades y pueblos, y nacionalidades (art. 56 y 57 ).

Sin embargo, estas denominaciones/significantes foráneos no lograrán a expresar la magnitud de su identidad en todas sus dimensiones, especialmente en lo geográfico puesto que los aymaras y quechuas de Bolivia comprenden su identidad o la reconstrucción de la misma reflejada en la reivindicación de la tierra, por medio de su comunidad o ayllu, marka, suyu, logrando conformar en versión macro, el Kollasuyu (Bolivia), lucha que enfrentan desde antes del período colonial y que continua en la actualidad con diversos tipos de movimientos "indígenas".

En cambio, los kichwas del Ecuador no se reflejan en los ayllus, lo que no significa que hayan perdido sus reivindicaciones territoriales. Su estructura organizacional responde más bien a los antecedentes históricos de la Colonia y República, los cuales, posteriormente, se combinaron con elementos externos (occidentales) reduciéndoles en "comunas" y en "comunidades indígenas" para que integrasen las "parroquias", logrando estructurar geográfica y administrativamente el territorio de los kichwas en forma de diferentes organizaciones indígenas con distintas concepciones políticas, étnicas y sociales en la actualidad.

Denominarlos como nación/nacionalidad en la compresión occidental es volver a caer en un lenguaje hegemónico deconstructivo de dominación que vuelve a llevarlos a una especie de tutela dentro el Estado. Reconocerlos en su verdadera 
denominación jaque/runa, ayllu, marka, suyu/señorio, Kollasuyu (Bolivia) Chinchaisuyu (Ecuador) es retomar sus antecedentes geográficos y con ello, toda su administración económica, política y social, dando lugar al rompimiento de los límites geográficos de los Estados en los que se encuentran.

\section{Reflexiones finales}

Durante aproximadamente cinco siglos, los jaques/runas, ayllus, markas, suyus, señorios aymaras, quechuas $y$ kichwas recibieron diversos significantes/denominativos como resultado de la hegemonía del lenguaje, formando el paradigma de la denominación y dominación a partir del conquistador, criollo, Estado de derecho, terrateniente, oligarca y élite.

Este paradigma permitirá que su ser sea deconstruido en su identidad milenaria e histórica, el Sumak Kawsay (Buen Vivir), Suma Qamaña (Vivir Bien) el cual puede ser interpretado como un "todo inter-relacionado", porque comprende aspectos geográficos, políticos, económicos y sociales.

Así los significantes y su relación con los respectivos significados históricos coloniales y postcoloniales, construirán una identidad necesitada de protección y tutela, repercutiendo en ideologías y políticas como el indigenismo, las cuales impregnaron la doctrina de los ordenamientos jurídicos nacionales e internacionales.

Hoy se manifiesta bajo una nueva faceta: el neo-indigenismo, vigente en los Estados plurinacionales de Bolivia y Ecuador, quienes han reconocido a los aymaras, quechuas $y$ kichwas bajo una nueva denominación/significante "naciones/nacionalidades"; sin embargo, interpretarlos y comprenderlos bajo una identidad ajena y circunscribirlos dentro de un Estado, es ser parte de la violencia estructural de siglos. Esto es así debido a que los aymaras se expanden geográficamente en los territorios de Bolivia (occidente), Perú (sur), parte de Chile (norte) y Argentina (norte). Por su parte, los quechuas y kichwas se extienden en los territorios de Bolivia, Ecuador, y parte de Colombia.

Por tanto, existe un paradigma de la denominación (significante) y dominación (significación), el cual sigue permitiendo la desestructuración identitaria de estas comunidades y no permite su emancipación histórica. Por tanto, se hace necesario salir de las estructuras coloniales y postcoloniales ya que han traído históricamente, sufrimiento, injusticia y subordinación entre los seres humanos. Realizar este cambio es un desafío dirigido a quienes ya no quieren ser parte de un sistema injusto de opresión y sufrimiento.

\section{Bibliografía}

APAZA HUANCA, Y. (2016), Hacia la emancipación de los aymaras, quechuas y kichwas desde su paradigma identitaria: Suma Qamaña, Sumak Kawsay, Universidad Carlos III de Madrid, Instituto de Derechos Humanos Bartolomé de las Casas, España. Disponible en: http://hdl.handle.net/10016/23314 (fecha de consulta el 26 de enero de 2018).

BORAH, W. (1985), "El status jurídico de los indios en Nueva España", América Indígena. vol. 45, núm. 2.

BOLIVIA (1826), Constitución Política del Estado. Disponible en: http://www.oocities.org/derechoconstitucional2001/cpe1826.htm (fecha de consulta el 28 de agosto de 2017).

BUNGE, M. (2001), Diccionario de filosofía, Siglo XXI, México. Disponible en: books.google.es/books?isbn=9682322766, 9789682322761 (fecha de consulta el 28 de agosto de 2017). 
CABEDO MALLOL, V. (2004), Constitucionalismo y Derecho Indígena en América latina, Universidad Politécnica de Valencia, España. Disponible en: http: books.google.es/books?isbn= 8497056051, 9788497056052 (fecha de consulta el 28 de agosto de 2017).

CUSI YUPANQUI, T. (1973), Relación de la Conquista del Perú, Horizonte, Perú.

DE LAS CASAS, B. (1975), Del único modo de atraer todos los pueblos a la verdadera religión, Fondo de Cultura Económica.

DE LAS CASAS, B., SAINT-LU, A. (1986), Historia de las Indias, Fundación Biblioteca de Ayacucho, Madrid. Disponible en: http://www.iphi.org.br/sites/filosofia brasil/Bartolom\%C3\%A9 de Las Casas Hist\%C3\%B3ria de las Indias I.pdf (fecha de consulta el 2 de marzo de 2018).

DE REINA, C. (1960), La Santa Biblia: Edición de Promesas, Unilit, Miami.

DERRIDA, J. (1998), De la gramatología, Siglo XXI, México. Disponible en: http://www.praxis-ylenguaje.es/materiales/ (fecha de consulta el 28 de agosto de 2017).

ECUADOR (1830), Constitución Política del Estado. Disponible en: http://www.cancilleria.gob.ec/wp-content/uploads/2013/06/constitucion_1830.pdf (fecha de consulta: 28 de agosto de 2017).

ESPAÑA (1973) 1681, Recopilación de Leyes de los Reynos de las Indias (tomo segundo), Cultura Hispánica, Madrid.

GINES DE SEPULVEDA, J. (1982), Tratado sobre las justas causas de la guerra contra los indios, Fondo de Cultura Económica, México.

GOTKOWITZ, L. (2007), "Bajo el dominio del indio: movilización rural, la ley y el nacionalismo revolucionario en Bolivia en la década de 1940". En: ALJOVÍN DE LOSADA, C., JACOBSEN, N., Cultura política en los Andes (1750-1950), Perú, Centro de Producción Fondo Editorial Universidad Nacional Mayor de San Marcos. Disponible en: http: books.google.es/books?isbn= 9972463532, 9789972463532 (fecha de consulta el 1 de marzo de 2018).

GUERRERO, A. (1991), La semántica de la dominación: el concertaje de los indios, Librimundi, Ecuador.

GUERRERO, A. (1994), "Una imagen Ventrílocua: El discurso liberal de la desgraciada raza indígena a fines del siglo XIX”. En: MURATORIO, B. (Ed.), Imágenes e imagineros, Flacso, Ecuador. Disponible en: http://www.flacsoandes.edu.ec/biblio/catalog/resGet.php?resld=14702 (fecha de consulta el 28 de agosto de 2017).

HANKE, L. (1958). El prejuicio racial en el nuevo mundo (Aristóteles y los indios de Hispanoamérica), Colección América Nuestra Universitaria, Chile.

MALAGA MEDINA, A. (1974), "Las reducciones en el Perú durante el gobierno del Virrey Toledo", Kollasuyo, núm. 87. Disponible en: http://www.iheal.univparis3.fr/sites/www.iheal.univparis3.fr/files/las\%20reducciones\%20en\%20el\%20Peru\%20Malaga.pdf (fecha de consulta el 1 de marzo de 2018).

MARROQUIN, A. (1972), Balance del indigenismo, Instituto Indigenista Interamericano, México.

MAZARIEGOS, M. (2014), Por el derecho a la consulta y disenso. Por el uso contrahegemónico del Derecho, Universidad Carlos III de Madrid, Instituto de Derechos Humanos Bartolomé de las Casas, España. Disponible en: http://hdl.handle.net/10016/19134 (fecha de consulta el 28 de agosto de 2017).

QUINTERO LOPEZ, R. (1986), "El Estado terrateniente del Ecuador (1809-1895)". En: PAUL DELER, J., SAINT-GEOURS Y., Estados y Naciones en los Andes (Hacia una historia comparativa: Bolivia-Colombia- Ecuador-Perú) Volumen 1, Perú, Instituto de Estudios Peruanos.

RAMIREZ, A. (2011), "Indio/indígena, 1750-1850", Historia Mexicana, núm. 3. Disponible en: http://www.jstor.org/stable/41151295?origin=JSTOR- 
pdf\&seq=1\#page scan tab contents (fecha de consulta el 28 de agosto de 2017).

THURNER, M. (2010), "Los indios y las repúblicas entre 1830-1880". En: MAIGUASHCA, J., Historia de América Andina Vol. 5: Creación de las repúblicas y formación de la nación, Libresa, Ecuador.

ZARATE, J. (2001). Los señores de la utopía: etnicidad política en una comunidad p'urhépecha: Santa Fe de la Laguna, Ueamuo, El Colegio de Michoacán A.C., México. Disponible en: books.google.es/books?isbn=9706790527, 9789706790521 (fecha de consulta el 1 de marzo de 2018). 